\title{
Analisis Struktur Skeleton Embrio Kadal (Mabouya multifasciata) dengan Pewarnaan Alizarin Red
}

\author{
Skeleton Structure Analysis of the Lizard Embryo (Mabouya multifasciata) \\ with Staining Alizarin Red \\ Nur Khasanah $^{1 *}$, Hari Santoso $^{2 * *}$, Ratna Djuniwati Lisminingsih ${ }^{3}$ \\ ${ }^{123}$ Jurusan Biologi Fakultas Matematika dan Ilmu Pengetahuan Alam Universitas Islam Malang, Indonesia
}

\begin{abstract}
ABSTRAK
Struktur pertumbuhan tulang pada setiap masing-masing organisme mempunyai pola berbeda dan persamaan. Pada embrio kadal osifikasi terjadi semasa fase telur dalam tubuh induk sebelum dilahirkan. Tujuan penelitian untuk mengetahui struktur tulang embrio berumur 48 hari. Metode penelitian menggunakan kualitatif dengan teknik pengambilan sampel purposive sampling dan pewarnaan alizarin red. Menggunakan embrio kadal (Mabouya multifasciata) sebanyak enam ekor diambil langsung dari perut induknya. Analisis adalah menghitung panjang tulang vertebrae dan ekstremitas. Hasil yang telah didapat adalah tulang ekstremitas dan vertebrae yang telah berwarna merah. Bagian tulang ekstremitas anterior yang telah terosifikasi adalah humerus, radius, ulna, falang dan cakar. Pada tulang ekstremitas posterior yang sudah mengalami osifikasi adalah femur, fibula, tibia, falang dan cakar. Tulang vertebrae yang sudah mengalami osifikasi adalah vertebrae servikalis, vertebrae torakalis, vertebrae lumbalis, vertebrae sacralis dan vertebrae caudalis. Sedangkan tulang di bagian ekstremitas posterior yang belum mengalami osifikasi yaitu carpal dan metacarpal.
\end{abstract}

Kata Kunci : kadal, alizarin red, struktur tulang

\begin{abstract}
The bone growth on any organisms have different patterns and equity. In the embryo of ossification lizards happened it during the eggs in the body of the parent before was born. The research aim is to find a bone structure of the embryo that was 48 days old. The method used qualitative with the technique of purposive sampling and alizarin red staining. Using the six embryos of lizards (mabouya multifasciata) and it was taken directly from the mother. The analysis used is counting the long of vertebrae and extremitie. The obtained results were the red colur on limb and vertebrae. Sections of the anterior extremity which undergoes ossification is the humerus, radius, the ulna, phalanges and claws. The posterior extremity which ossification is the femur, the fibula, the tibia, phalanges and claws. The vertebrae bone that it hapened ossification was cervical vertebrae, vertebrae thoracic, lumbar vertebrae, sacralis vertebrae and caudalis vertebrae. Whereas a bone in the part of the limb posterior ones which are not hapened ossification is the carpal and metacarpal.
\end{abstract}

Keywords : lizard, alizarin red, bone structure

*) Nur Khasanah, Jurusan Biologi FMIPA UNISMA, Jl. MT Haryono 193, Malang 65144 Telp. 081537625326 email: nur704251@gmail.com

**) Drs. H. Hari Santoso, M.Biomed, Jurusan Bologi FMIPA UNISMA, Jl. MT Haryono 193, Malang 65144 Telp. 082331449560 Email: Harisantoso.m.biomed@gmail.com

Diterima Tanggal 4 Pebruari 2019 - Diterbitkan Tanggal 25 Januari 2020 


\section{Pendahuluan}

Setiap organisme mempunyai cara tersendiri untuk berkembangbiak. Salah satu bentu dari perkembangbiakan adalah secara ovovivipar (bertelur dan beranak). Kadal adalah satu hewan yang cara berkembangbiaknya dengan cara ovovivipar. Telur kadal akan menetas di dalam tubuh induk kadal dan setelah beberapa waktu akan keluar bersama cangkang telur melalui kloaka. Embrio kadal ini memperoleh cadangan makanan dari dalam cangkang telur [1].

Storer dan Usinger [2] mengemukakan bahwa kadal memiliki badan panjang dengan kepala yang jelas, leher, dan ekor. Ekor vertebre belum mengalami osifikasi sempurna. Osifikasi adalah proses perkembangan tulang dari embrio sampai dewasa, proses osifikasi tersebut menggunakan metode pewarnaan alizarin red. Alizarin red merupakan suatu metode pewarnaan tulang yang digunakan untuk mendeteksi proses osifikasi pada tulang hewan.

Penelitian terakhir yang dilakukan oleh Luthfi [3] mengenai "kalsifikasi skeleton aksial pada regenerat ekor kadal (Mabouya multifasciata)" merupakan penelitian yang dilakukan untuk mengetahui kalsifikasi pada regenerat ekor kadal jantan dewasa berekor asli yang diautotomi ekornya. Penelitian ini dilakukan untuk menganalisis struktur skeleton pada embrio kadal. Analisis struktur skeleton ini nantinya akan dapat digunakan pada usaha peternakan untuk menentukan pakan apa saja yang nantinya dapat digunakan untuk mempercepat tumbuhnya tulang Penelitian mengenai struktur skeleton pada embrio kadal sendiri belum banyak dilakukan oleh karena itu peneliti tertarik untuk meneliti struktur tulang pada embrio kadal ini.

\section{Material dan Metode}

\section{Bahan dan Alat}

Bahan yang digunakan adalah kadal (Mabouya multifasciata) bunting, kloroform, aquades, alcohol PA 95\%, Larutan pewarna Alizarin red, Larutan KOH 1\%, Larutan gliserin murni, Timol untuk mencegah pertumbuhan jamur. Alat yang digunakan adalah satu set alat bedah dan paraffin blok, pipet tetes, gelas beker, enlenmeyer, cawan petri, labu ukur, gelas ukur, toples kecil, tempat specimen, mikroskop, jangka sorong dan mistar

\section{Metode}

Desain penelitian yang digunakan pada penelitian ini adalah penelitian kualitatif dengan metode pengambilan sampel yaitu teknik penelitian purposive sampling.

\section{Cara Kerja}

Kadal (Mabouya multifasciata) bunting yang telah didapat dianestesi secara inhalasi menggunakan kloroform. Setelah itu dilakukan pembedahan untuk mengambil embrio kadal. Embrio kadal yang sudah didapat, kemudian diwarnai menggunakan metode Alizarin red [4] yang telah dimodifikasi dengan cara yakni: Direndam garam fisiologis untuk menghambat terjadinya kerusakan pada jaringan, direndam alcohol hingga warna otot terlihat putih pucat. Direndam $\mathrm{KOH} 1 \%$ agar otot transparan, direndam alizarin red hingga skeleton berwarna merah atau ungu, direndam $\mathrm{KOH} 1 \%$ hingga otot benar-benar transparan, dijernihkan dengan larutan penjernih, diberi larutan tymol untuk mencegah tumbuhnya jamur. Embrio yang telah diwarnai kemudian dianalisis struktur skeletonnya.

Analisis Data: Pengamatan pada penelitian ini menggunakan mikroskop stereo. Diamati tulang yang telah mengalami osifikasi dengan ditunjukkannya warna merah yang telah terwarnai. Setelah tulang diwarnai diukur panjang tulang ekstremitas dan Vertebrae dari 6 embrio yang telah terwarnai lalu di hitung rata-ratanya pada tiap tulang. 


\section{Hasil dan Diskusi}

Hasil penelitian yang didapat adalah induk kadal bunting dengan ciri-ciri ukuran bagian perut lebih besar daripada bagian leher. Pada penelitian ini ukuran leher adalah 4,2 $\mathrm{cm}$ lebih kecil dari ukuran lingkar pinggang $7,9 \mathrm{~cm}$ dengan panjang tubuh $21,8 \mathrm{~cm}$. setelah dibedah dan diambil embrionya dan dan dianalisis, embrio berumur 48 hari kebuntingan. Embrio pada hewan Lacertilia memiliki ciri-ciri yakni proyeksi kranial pada daerah otak telah menghilang, dan otakpun hilang tidak terlihat secara eksternal[5]. Pigmen kulit telah menyebar ke seluruh tubuh dan bersisik sepenuhnya hingga pada bagian tungkai pun juga sudah tertutupi oleh sisik. Kelopak mata pada hari ke-48 kehamilan ini juga sudah menutupi seluruh mata. Setelah diwarnai menggunakan alizarin red warna tulang yang awalnya tidak terlihat menjadi berwarna merah karena adanya ikatan antara alizarin red dengan ion kalsium yang ada pada tulang [6].

Tabel 1. Hasil Pengukuran Panjang Tulang Menggunakan Jangka Sorong

\begin{tabular}{llccccccc}
\hline & & \multicolumn{6}{c}{ Ekstremitas } & \multicolumn{5}{c}{ Vertebrae } \\
\cline { 3 - 8 } No. & Sampel & $\begin{array}{c}\text { Anterior } \\
(\mathrm{cm})\end{array}$ & $\begin{array}{c}\text { Posterior } \\
(\mathrm{cm})\end{array}$ & $\begin{array}{c}\text { Servikalis } \\
(\mathrm{cm})\end{array}$ & $\begin{array}{c}\text { Torakalis } \\
(\mathrm{cm})\end{array}$ & $\begin{array}{c}\text { Lumbalis } \\
(\mathrm{cm})\end{array}$ & $\begin{array}{c}\text { Sakralis } \\
(\mathrm{cm})\end{array}$ & $\begin{array}{c}\text { Caudalis } \\
(\mathrm{cm})\end{array}$ \\
\hline 1. & Embrio 1 & 1,65 & 1,04 & 0,65 & 1,45 & 3,75 & 1,25 & 4,00 \\
2. & Embrio 2 & 1,45 & 0,85 & 0,95 & 1,55 & 3,60 & 1,30 & 4,20 \\
3. & Embrio 3 & 1,40 & 0,85 & 0,60 & 1,40 & 3,60 & 1,25 & 4,15 \\
4. & Embrio 4 & 1,35 & 0,85 & 0,65 & 1,65 & 3,70 & 1,15 & 4,20 \\
5. & Embrio 5 & 1,30 & 0,75 & 0,90 & 1,65 & 3,65 & 1,25 & 4,15 \\
6. & Embrio 6 & 1,40 & 0,95 & 0,60 & 1,55 & 3,60 & 1,30 & 4,15 \\
7. & Rata-rata & 1,42 & 0,88 & 0,72 & 1,55 & 3,65 & 1,25 & 4,14 \\
\hline
\end{tabular}

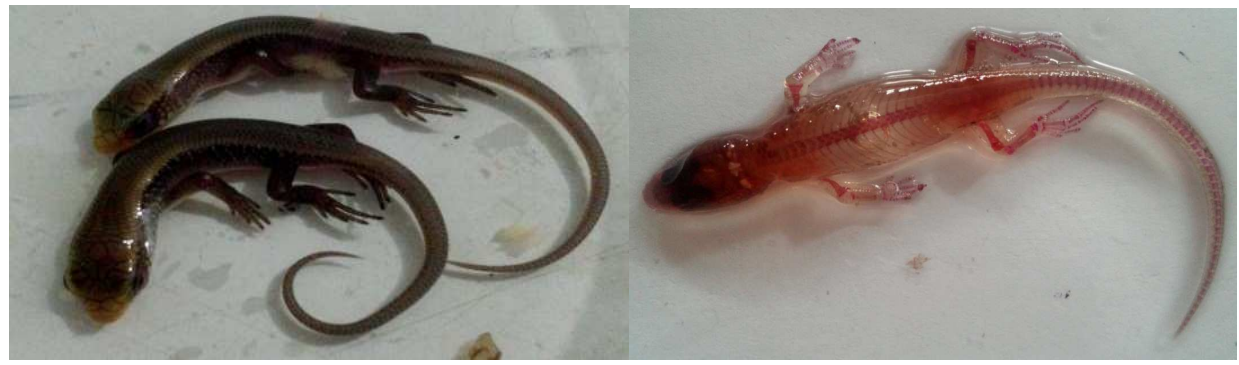

Gambar 1. Embrio Sebelum dan Sesudah diwarnai Alizarin Red

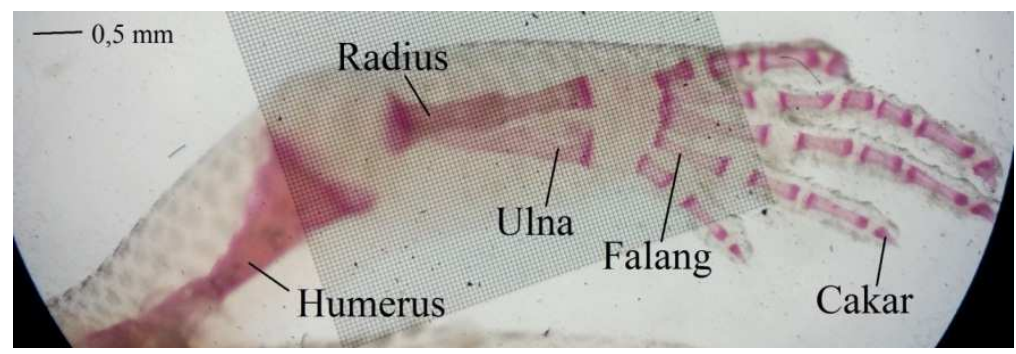

Gambar 2. Tulang ekstremitas anterior (kanan) preparat embrio setelah diwarnai dilihat dibawah mikroskop perbesaran 30 kali. 


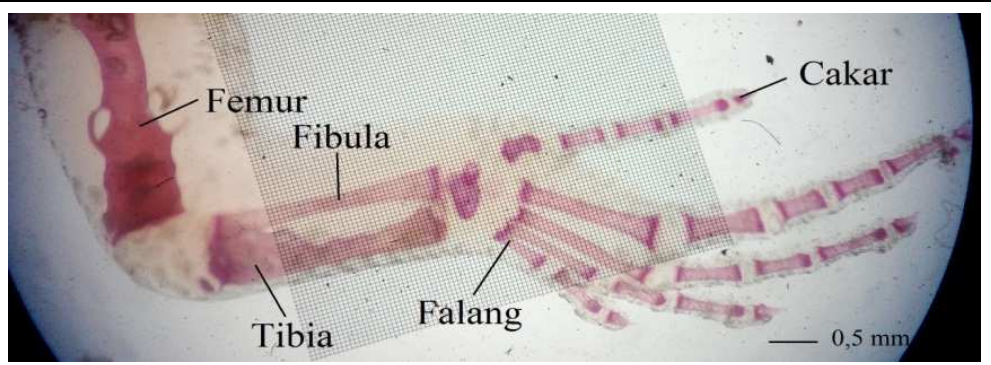

Gambar 3. Tulang ekstremitas posterior (kiri) preparat embrio yang telah diwarnai dilihat dari bawah mikroskop perbesaran 30 kali.

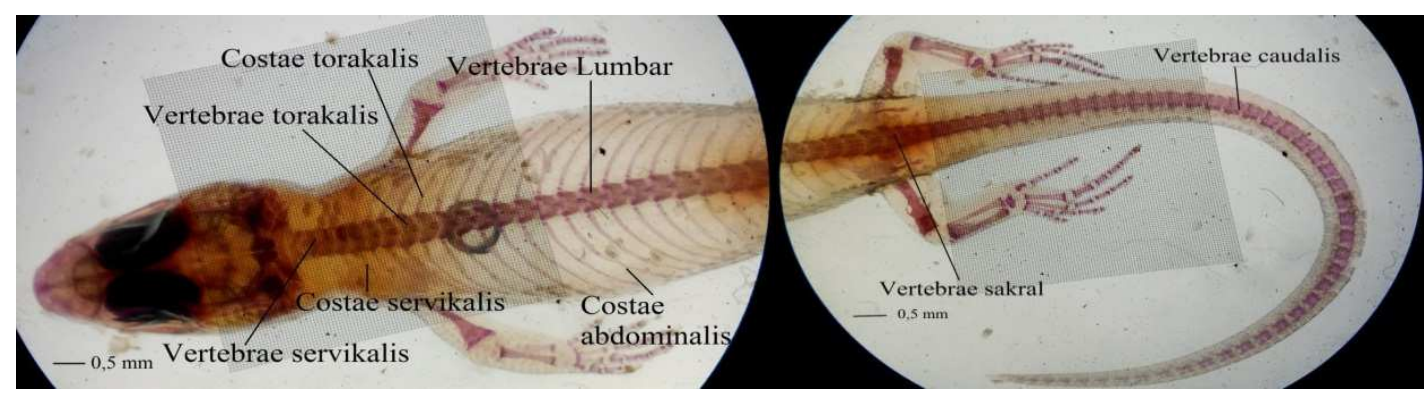

Gambar 4. Vertebrae preparat dibawah mikroskop perbesaran 30 kali.

Hasil pengukuran panjang dibagian ekstremitas dan Vertebrae menunjukkan bahwa pada embrio umur 48 hari sudah mengalami osifikasi di bagian tulang ekstremitas dan Vertebrae. Pada tulang ekstremitas anterior didapat hasil pengukuran panjang rata-rata pada 6 embrio yang telah diwarnai yaitu 1,42. Pada bagian ekstremitas posterior memiliki panjang rata-rata $0,88 \mathrm{~cm}$. Rata-rata panjang dari Vertebrae servikalis, torakalis, lumbalis, sakralis dan caudalis secara berturut-turut adalah $0,72 \mathrm{~cm} ; 1,55 \mathrm{~cm} ; 3,65 \mathrm{~cm} ; 1,25 \mathrm{~cm}$ dan $4,14 \mathrm{~cm}$.

Analisis Tulang Ekstremitas dan Vertebrae: Tulang ekstremitas terbentuk melalui proses osifikasi endokondral. Pada proses osifikasi ini, jaringan tulang terbentuk dari sel mesenkim. Tulang ekstremitas terbentuk dari pembuluh darah yang merangsang sel pericardium menjadi osteoblast. Tulang ekstremitas ini akan mengalami perpanjangan seiring dengan bertambahnya umur dari kadal. Tulang kadal yang awalnya berupa tulang rawan lama kelamaan akan berubah menjadi tulang keras. Tulang ekstremitas pada kadal berfungsi sebagai alat gerak. Pada kadal, ekstremitas terdiri dari dua bagian yakni ekstremitas anterior dan ekstremitas posterior. Ekstremitas anterior terdiri dari Humerus, radius, ulna, falang dan cakar. Humerus yang bentuknya seperti pipa yang melebar dibagian posterior terlihat sudah terbentuk tulang rawan. Pada tulang radius nantinya akan berartikulasi dengan humerus dan ulna saat digunakan untuk bergerak. Tulang radius pada hasil pengamatan dibawah mikroskop terlihat bahwa warna tulang setelah diwarnai yaitu merah tua yang berarti tulang sudah terbentuk tulang rawan. Bentuk dari tulang radius seperti pipa memanjang. Pada falang, jumlah tulang pada poluks, secundus, medium, numulus dan minimus secara berturt-turut adalah 2, 3, 4, 5 dan 3 yang masih belum menyatu sama lain. Pada kadal yang sudah dewasa, jumlah tulang tulang jumlah tulang pada poluks, secundus, medium, numulus dan minimus adalah 3, 3, 2, 2 dan 2 [7]. Untuk falang, tulang yang terlihat juga berbentuk seperti pipa yang tersusun belum menyatu sama lain dengan warna tulang yang telah terwarnai belum menunjukkan warna merah yang gelap (merah tua). Falang akan bertambah panjang dan menyatu sama lain dan tidak mengalami pertambahan jumlah tulang. Pada cakar, tulang yang teramati berbentuk seperti pipa namun meruncing di daerah ujungnya. 
Pada tulang di bagian ekstremitas posterior terdiri dari femur, tibia, fibula, tarsal, metatarsal, falang dan cakar. Pada hasil yang telah diperoleh, terlihat bahwa tulang tarsal dan metatarsal belum terbentuk. Pada bagian ekstremitas posterior ini, carpal dan metacarpal belum tumbuh karena saat pewarnaan tulang tidak terlihat tulang berwarna merah. Tulang yang sudah berbentuk tulang rawan adalah tulang femur dengan intensitas warna yang lebih gelap daripada hasil pewarnaan pada bagian tibia, fibula, falang dan cakar.

Tulang pada falang di bagian ekstremitas posterior berjumlah 3 tulang hallux. Pada bagian secundus terdapat 3 tulang yang belum menyatu sama lain. Pada bagian falang yang terdapat dibagian tengah atau biasa disebut tulang medium memiliki jumlah tulang yang terlihat dibawah mikroskop yaitu 4 tulang yang masih belum menyatu sama lain. Tulang-tulang pada daerah medium ini setelah mendapat cukup kalsium akan akan berkembang dan menyatu menjadi 2 tulang. Tulang yang paling kecil atau biasa disebut bagian tulang minimus memiliki jumlah tulang yang telah terwarnai yaitu 2 tulang. Tulang pada daerah minimus ini nantinya akan mengalami perpanjangan seiring dengan perkembangan yang terjadi. Cakar embrio pada bagian ekstremitas posterior berbentuk meruncing pada ujungnya yang masih berbentuk kartilago karena warna yang dihasilkan masih berwarna merah muda dan warna merah yang memudar. Cakar pada embrio kadal ini setelah mengalami perkembangan akan menjadi kuat karena membentuk tulang keras. Cakar pada kadal nantinya akan digunakan untuk berjalan diatas tanah maupun di dahan-dahan pohon.

Pada kadal tulang Vertebrae terdapat 5 bagian yakni Vertebrae servikalis, Vertebrae torakalis, Vertebrae lumbalis, Vertebrae sacralis dan Vertebrae caudalis. Menurut Sukiya [8] jumlah Vertebrae servikalis sekitar 9 baris, 10 torak, 5 lumbal, 2 sakral dan 39 bagian Vertebrae caudalis. Pada hasil penelitian ini Vertebrae servikalis yang terhitung adalah 6 baris tulang yang tersusun rapat berbentuk ulat melingkar. Pada Vertebrae torakalis, jumlah tulang yang terhitung adalah 4 baris yang bentuknya sama seperti tulang Vertebrae servikalis. Vertebrae lumbalis pada penelitian ini tercatat terdapat 16 baris tulang yang tersusun menyatu sama lain dengan bentuk seperti mahkota. Tulang Vertebrae lumbalis ini masih berbentuk tulang kartilago karena intensitas warna tulang setelah diwarnai adalah merah muda. Untuk tulang Vertebrae sacralis jumlah tulang yang tercatat adalah 2 baris.

Vertebrae caudal adalah bagian tulang yang paling panjang. Pada kadal dewasa vertebre caudalis ini bisa berukuran lebih panjang dari bagian tubuhnya. Vertebrae caudalis berbentuk persegi yang melebar ke samping yang tersusun rapat dari anterior ke posterior. Jumlah Vertebrae caudalis pada penelitian tercatat sebanyak 47 dengan tulang yang tersusun rapat. Menurut Alibardi dan Sala [8] mengatakan bahwa tulang rawan pada bagian ekor sudah menunjukkan adanya kalsifikasi pada bagian sisi dalam maupun luar tabung tulang rawan. Namun, Osifikasi pada Vertebrae caudalis ini belum mengalami osifikasi sempurna sehingga kadal dapat memutuskan ekornya (autotomi) ketika kadal dalam bahaya.

\section{Kesimpulan}

Berdasarkan hasil penelitian dan hasil yang telah diperoleh, dapat disimpulkan bahwa embrio kadal yang berumur 48 hari sudah mengalami proses osifikasi dengan ditunjukkannya warna merah setelah embrio diwarnai dengan alizarin red. Pada tulang ekstremitas anterior sudah terbentuk humerus, radius, ulna falang dan cakar. Pada ekstremitas posterior sudah terdapat tulang femur, tibia, fibula, falang dan cakar belum terdapat carpal dan metacarpal. Sedangkan pada tulang Vertebrae semua bagian tulang Vertebrae sudah mengalami osifikasi dan tersusun menyatu satu sama lain.

\section{Daftar Pustaka}

[1] Das, I. 2010. Reptiles of South-East Asia. New Holland Publishers. UK.

[2] Storer, I. Tracy, Usinger, Robert L, 1957. General of Zoology. Mc Graw Hill Book Company Inc, New York. 
e-Jurnal Ilmiah BIOSAINTROPIS (BIOSCIENCE-TROPIC)

Volume 5/ No.: 2 / Halaman 97 - 102 / Januari Tahun 2020

ISSN : 2460-9455 (e) - 2338-2805(p)

[3] Luthfi, M. J, Soesilo, N.P. Sagi, M. 2003. Kalsifikasi Skeleton pada Regenerat Ekor Kadal (Mabouya multifasciata Kuhl). Jurnal Berkala Ilmiah Biologi Vol. 3, No.1: 1-8.

[4] Nugroho, G. 2016. Struktur Skeleton Sirip Kaudal Komplek Perophtalmus gracilis. Jurnal Ilmiah Biogenesis, Vol.4 No.1:29-33.

[5] Ollonen, J. 2018. Skull Defelopment, OssificationPattern And adult shape in the Emerging Lizard Model Organism Pogona vitticeps : A Comparative Analysis with Other Squamates. Fronties in Physiology 278:1-26

[6] Kienan, J.A. 1981. Histologycal and Histochemical Methods : Theory and Practice. Pergamon Press. England.

[7] Jordan, E.L. and P.S. Verma. 1983. Chordate Zoology and Elements of Animal Physiology. 5th ed. S. Chard \& Company Ltd. Ram Nagar. New Delhi.

[8] Sukiya, 2005. Biologi Vertebrata. Universitas Negeri Malang (UM Press). Malang.

[9] Alibardi, L dan Sara, M.1981. Indagini Ishtochimiche Sulla Struttura Dela Cartilagine Rigenerata Nella Coda di Lacerta situla. Arch. Ital.. Anat. Embriol. 86 163-178 